\title{
AVALIAÇÃO DO PLANO NACIONAL DE EDUCAÇÃO 2001-2009: QUESTÕES ESTRUTURAIS E CONJUNTURAIS DE UMA POLÍTICA
}

\author{
Luiz Fernandes Dourado*
}

\begin{abstract}
RESUMO: Este artigo avalia o Plano Nacional de Educação (PNE) em vigor, a lógica política de sua tramitação e sua aprovação pelo Congresso Nacional, ressaltando as concepções de educação e de Estado em disputa, os seus limites estruturais e conjunturais como política pública, bem como os contornos assumidos no enfrentamento das questôes da educação básica e superior. Apresenta, ainda, reflexôes e indicações sobre a temática, e enfatiza a necessidade histórica da proposição e construção coletiva do novo PNE (2011-2020), a fim de que se constitua uma efetiva política de Estado para a educação.
\end{abstract}

Palavras-chave: Plano Nacional de Educação. Políticas educacionais. Educação. Avaliação. Gestão.

\section{EVALUATION OF THE 2001-2009 NATIONAL PLAN FOR EDUCATION: STRUCTURAL AND SHORT-TERM QUESTIONS IN A POLICY}

ABSTRACT: This paper assesses the current National Plan for Education (NPE), the political logic of its progress and its approval by the National Congress. It emphasizes the conceptions of education and of State in dispute, its structural and short-term limits as a public policy, as well as the outlines referring to basic and higher education. It also presents reflections and indications on

Doutor em Educação e professor titular da Universidade Federal de Goiás (UFG).

E-mail:douradol@terra.com.br

Educ. Soc., Campinas, v. 31, n. 112, p. 677-705, jul.-set. 2010 
Avaliação do Plano Nacional de Educação 2001-2009: questôes estruturais e conjunturais...

this theme and highlights the historical need for the proposition and collective construction of the new 2011-2020 NPE, so that it constitutes an effective state policy for education.

Key words: National Plan for Education. Education policy. Education. Evaluation. Management.

\section{Estado, educação, políticas e avaliação}
7 relação entre Estado, educação e políticas educacionais é marcada por processos e dinâmicas complexas, que traduzem a historici- dade das relações sociais mais amplas, suas prioridades e formas ideológicas.

É importante analisar essas relações e destacar as múltiplas conexões que as demarcam, estrutural e conjunturalmente, num determinado espaço histórico-social. Tais conexóes traduzem o movimento do real, por meio do tensionamento entre base material e superestrutura. As formas ideológicas, nesse cenário, devem ser entendidas, de acordo com Gramsci, como o "(...) significado mais alto de uma concepção de mundo, que se manifesta implicitamente na arte, no direito, na atividade econômica, em todas as manifestações de vida individuais e coletivas (...)" (Gramsci, 1986, p. 16). Assim, variadas são as formas de se conhecer e de se explicar a realidade, cuja produção é historicamente dotada de peculiaridades próprias.

O caminho analítico deste artigo, portanto, busca avaliar o Plano Nacional de Educação como política pública, na qualidade de expressão da articulação entre epistemologia e política, subjetividade e objetividade, cotidiano e estrutura social. Esta análise parte do pressuposto de que a avaliação de uma política pública é sempre resultante das condições objetivas em que ela é proposta e/ou efetivada e, neste sentido, deve ser resultante do exercício acadêmico pautado pela razão crítica presente nos embates e nas opções teóricas perante o conhecimento hodierno.

Nesse sentido, a ciência ${ }^{1}$ é entendida como a expressão das relações sociais, de seus nexos, desenvolvimentos e complexidade, apresentando-se como campo, cuja construção é mediatizada pela ideologia. Tal compreensão é indicadora dos limites que se interpõem à produção do conhecimento e das possibilidades da avaliação, na medida em que nos possibilitam uma verdade aproximada do real, pois "o objeto é sempre 
inatingível (...). Neste sentido o objeto do conhecimento é uma 'representação’ feita pela teoria, tentando reproduzir o real (...)” (Cardoso, 1978, p. 26).

A análise do PNE, na seara das políticas educacionais, explicita, portanto, processo e concepções em disputa, suscitando, ainda, particularidades, que nos permitem indicar o duplo papel ideológico desse movimento - a negação e, paradoxalmente, a participação da sociedade nas questões educacionais -, mediatizado por uma concepção política, cuja égide consiste, no campo dos direitos sociais, na prevalência de uma cidadania regulada e, consequentemente, restrita.

Compreender os nexos interinstitucionais de implementação de políticas educacionais, por meio de uma política pública, no caso o PNE, implica destacar que as imbricações entre a realidade social dinâmica e os atores sociais são permeadas por categorias analíticas (teóricoconceituais) e procedimentos políticos (fins visados), cuja materialização se efetiva na intersecção entre regulamentação, regulação e ação política, marcados por disputas que traduzem os embates históricos entre as classes sociais e, ao mesmo tempo, os limites estruturais que demarcam as relações sociais capitalistas.

Frigotto e Molina (2010, p. 38), ao abordarem a relação Estado, educação e sindicalismo, afirmam:

É pois da natureza do Estado, do sistema escolar e do sindicato moverse dentro da legalidade capitalista e tender a reproduzir suas relaçôes sociais; e dentro destas, as relações e práticas educativas. Mas tanto o Estado, quanto o sistema escolar e o sindicato, pela existência das classes sociais fundamentais (capital e trabalho) com interesses antagônicos, são alvo de uma disputa.

Ou seja, para compreender as políticas educacionais, é fundamental situar a concepção de Estado, ${ }^{2}$ entendida aqui em acepção ampla, que envolve sociedade civil e política, seus embates e os percursos históricos em que estas se constroem, tendo por marco as condições objetivas em que se efetivam a relação educação e sociedade, os processos sistemáticos ou não de gestão, bem como o papel das instituições educativas e dos diferentes atores que constroem o seu cotidiano.

Portanto, tal concepção revela que o processo educativo é mediado pelo contexto sociopolítico e cultural mais amplo, pelas condiçóes em 
Avaliação do Plano Nacional de Educação 2001-2009: questôes estruturais e conjunturais...

que se organiza a sociedade e pelos processos de regulamentação e regulação em que se realizam a institucionalização do direito social à educação, as dinâmicas organizacionais e, consequentemente, as políticas de acesso, permanência e gestão, que não se dissociam dos marcos estruturais da sociedade brasileira, fortemente marcados por uma tradição histórica, cujo ethos patrimonial não foi totalmente superado, onde a desigualdade social se faz presente num modelo societário desigual e combinado.

Nesse campo, a produção teórica e as políticas traduzem-se por um quadro polissêmico e, eminentemente, político-pedagógico. Ou seja, as análises e proposições na área educacional são portadoras de concepções de mundo, sociedade e educação, que, por sua vez, traduzem o lugar histórico e, portanto, político-ideológico de onde se inscrevem.

Assim, é fundamental situar, a priori, que em nossa análise a educação é entendida como um direito social fundamental e que sua efetivação se dá em um contexto caracterizado como um campo de disputas de concepções e projetos ${ }^{3}$ e, portanto, demarcada por posições políticas não apenas diferentes, mas substantivamente contraditórias. Isso significa dizer que a educação é um ato político que expressa diferentes concepções e não por acaso as políticas educacionais, na qualidade de políticas públicas, traduzem tais disputas. É fundamental, ainda, ressaltar que tais políticas expressam os limites e possibilidades resultantes das condições sociais mais amplas que configuram a sociabilidade capitalista.

A esse respeito e destacando que o planejamento, como instrumento de política pública, exprime embates, negociações e acordos, Azevedo (2010, p. 31-32) afirma:

Mas, num processo que é dinâmico, as políticas públicas constituem respostas a certos problemas, quase sempre demandados por grupos sociais que se organizam para lutar por soluções. $\mathrm{O}$ que não significa que as decisões, em uma determinada etapa, não serão modificadas e redesenhadas em etapas posteriores, podendo mesmo resultar, no curso de sua implementação, em resultados diferentes dos pretendidos. Em outras palavras, mesmo que uma política pública seja norteada por referenciais que privilegiem a garantia dos direitos sociais, os processos de sua implementação, em virtude dos distintos e contraditórios interesses em jogo, podem seguir rumos que acabam por reforçar desigualdades estruturais (...). 
Assim, esse campo de disputa se constroi por meio de limites estruturais e conjunturais que expressam a relação sociedade e educação. A avaliação do PNE, nessa ótica, implica compreender esse tensionamento entre a dinâmica política e organizativa mais ampla, o Plano e os vetos, a proposição e materialização de algumas políticas, bem como indicar alguns desafios no tocante à construção e proposição de novo PNE, a ser construído como política de Estado, com vistas à otimização e melhoria dos processos, planejamento e gestão, envolvendo os diferentes níveis e modalidades da educação nacional em busca de uma educação democrática e com qualidade como direito social para todos, sem perder de vista os limites da sociabilidade capitalista.

Não por acaso, a avaliação de políticas públicas, segundo Dourado (2006), tem se constituído um grande desafio para a área educacional, seja em função dos limites teóricos e metodológicos subjacentes ao seu grau de complexidade, pelo envolvimento de diferentes atores ou pelo seu desdobramento abrangente, envolvendo questões que transcendem o escopo da área educacional. A avaliação de políticas educacionais pode se efetivar por vários ângulos, concepções e perspectivas, que requerem uma análise contextualizada dos complexos contornos políticos que a engendram, uma vez que ela se apresenta por meio da tensão salutar entre a dimensão técnica e política, cujos horizontes teórico-ideológicos e políticos a traduzem como uma política de governo e/ou de Estado.

$\mathrm{Na}$ tradição histórica brasileira, as análises indicam que as políticas educacionais têm sido marcadas hegemonicamente pela lógica da descontinuidade/continuidade, por carência de planejamento de longo prazo e por políticas de governo, em detrimento da construção coletiva, pela sociedade brasileira, de políticas de Estado. ${ }^{4}$

Nesse cenário, marcado por desigualdades sociopolítico-culturais e econômicas, alguns avanços na democratização das políticas educacionais têm sido propostos e, em alguns casos, efetivados, ainda que tais políticas não sejam resultantes da efetivação do PNE como política de Estado e base para os processos de planejamento e gestão da educação nacional. Tal perspectiva alerta-nos para a complexa relação entre proposição e materialização de políticas, seus limites e possibilidades históricas, bem como para a necessária efetivação de políticas de Estado que traduzam a participação ampla da sociedade brasileira. Portanto, a avaliação na arena educacional deve considerar as condições sócio-político e culturais, 
Avaliação do Plano Nacional de Educação 2001-2009: questôes estruturais e conjunturais...

a legislação (regulamentação), o quadro complexo e desigual em que se efetivam as políticas e, ainda, as diferentes formas de regulação ${ }^{5}$ que interferem na materialização das políticas e que resultam da ação de vários atores institucionais ou não (professores, estudantes, pais, gestores, sindicatos...).

Tais sinalizações teóricas permitem apreender as bases em que se apresenta esta análise, bem como os seus limites e potencialidades, na medida em que o esforço teórico proposto busca resgatar a discussão das políticas educacionais a partir de sua articulação a processos mais amplos, que incluem mas não se restringem à dinâmica intraescolar, sem negligenciar, nesse percurso, a real importância do papel social da escola e dos processos de organização, cultura e gestão intrínsecos a ela. Assim, a opção de nossa análise se centrará na compreensão dos limites interpostos ao PNE em face da lógica que prescinde da ação do Estado, historicamente configurado em sua feição, stricto sensu, e em face de seus complexos contornos na proposição e materialização das políticas educacionais, que indicam potencialidades de uma ação mais ampla numa perspectiva de Estado ampliada.

PNE: seara de disputas e de limites estruturais e conjunturais

O atual PNE (Lei n. 10.172, de 9/1/2001) é resultado das ações da sociedade brasileira para garantir as disposições legais contidas no artigo 214 da Constituição Federal, de 1988, o qual sinaliza que "A lei estabelecerá o plano nacional de educação, de duração plurianual, visando à articulação e ao desenvolvimento do ensino, em seus diversos níveis, e à integração das açôes do poder público que conduzam à: I erradicação do analfabetismo; II - universalização do atendimento escolar; III - melhoria da qualidade do ensino; IV - formação para o trabalho; v - promoção humanística”, e das disposições transitórias da LDB que, em seu artigo 87 , parágrafo $1^{\circ}$, preconiza que a União deveria, no prazo de um ano, encaminhar ao Congresso Nacional proposta de PNE, indicando diretrizes e metas para os dez anos seguintes (Década da Educação), em sintonia com a Declaração Mundial sobre Educação para Todos.

O PNE teve tramitação sui generis, envolvendo o embate entre dois projetos: o PNE da sociedade brasileira e a proposta de $\mathrm{PNE}^{6}$ encaminhada pelo Executivo federal. Tais propostas expressavam concepções 
e prioridades educacionais distintas, sobretudo na abrangência das políticas, em seu financiamento e gestão.

A aprovação do atual PNE foi resultado, portanto, da hegemonia governamental no Congresso Nacional, que buscou traduzir a lógica das políticas governamentais em curso. O Governo FHC, por meio do Ministério da Educação, efetivou políticas e lógicas de gestão, visando implementar amplo processo de reforma da educação nacional, ${ }^{7}$ cujas prioridades se constituíram, hegemonicamente, pela adoção de políticas focalizadas, com forte ênfase no ensino fundamental, e pela efetivação de vários instrumentos e dispositivos, visando à construção de um sistema de avaliação da educação.

Corroborando essa compreensão, o ex-ministro da Educação do Governo FHC (Souza, 2005, p. 43-45) destaca, entre outros aspectos, como base para a reforma ministerial, o ensino fundamental e o sistema de avaliação, bem como a "busca de uma política integrada, mas diferenciada, segundo as particularidades de cada nível de ensino"; a descentralização da execução das políticas (envolvendo ação articulada com estados, municípios e escolas) e a revisão do arcabouço normativo. A esse respeito Souza (2005, p. 45) ressalta, do documento "Planejamento político-estratégico 1995-1998", como uma das importantes ações políticas do governo federal, a revisão do "arcabouço normativo para incentivar a inovação" que implicava:

1) retirar da Constituição dispositivos que engessam a gestão do sistema educacional; 2) aprovar uma nova Lei de Diretrizes e Bases que possibilite a diversificação institucional: novos cursos, novos programas, novas modalidades; 3 ) instituir um novo Conselho Nacional de Educação, mais ágil e menos burocrático; 4) modificar regulamentaçōes para garantir maior autonomia da escola; 5) transferir a ênfase dos controles formais e burocráticos para a avaliação de resultados.

Tais estratégias traduzem a compreensão da ação estatal como resultante da estrita prioridade governamental e que, nesse caso, implicou, inclusive, alterações e emendas à Constituição Federal vigente.

A respeito da revisão do arcabouço normativo, por meio de ação orgânica efetivada pelo governo federal, por intermédio do Ministério da Educação, destacaram-se, entre outras, as mudanças na Lei de Diretrizes e Bases que tramitava no Congresso Nacional e que, segundo Souza (2005, p. 46), era considerada pelo governo "um desastre, pois refletia apenas a 
Avaliação do Plano Nacional de Educação 2001-2009: questões estruturais e conjunturais...

visão e os interesses das corporações do segmento educacional”. A ação articulada e exitosa é registrada pelo autor (2005, p. 47), ao ressaltar as providências tomadas junto ao Congresso Nacional visando rever o processo de tramitação do projeto de lei. Segundo o autor (op. cit., p. 47), revertido o processo, a "lei finalmente aprovada na câmara (...) incorporou os princípios, a forma e o conteúdo do projeto do senador Darcy Ribeiro, muito diferente do que havia sido aprovado anteriormente". O autor destaca várias ações e avanços obtidos nos processos de regulamentação ${ }^{8}$ revelando a articulação do projeto educacional do governo federal no período de 1995-2002, mas, paradoxalmente, não faz referências ao processo de tramitação do PNE, que, como afirmamos anteriormente, foi apresentado pelo Legislativo e, em decorrência desse fato, foi alterado pela proposta enviada pelo Executivo federal, na qual prevaleceram as bases constitutivas das políticas em curso pelo governo no período. Tal fato evidencia a falta de centralidade conferida ao PNE em relação ao projeto de governo, mas, ao mesmo tempo, revela a ação política no sentido de que a proposta de PNE encaminhada e disputada funcionasse, em nível governamental, como agente inibidor de outras concepções contrárias à reforma, em curso, que advogavam o estabelecimento de políticas de Estado.

Nesse cenário, o PNE aprovado estruturou-se em capítulos e seções, em consonância com a organização da educação brasileira, em seus níveis e modalidades educacionais. ${ }^{9} \mathrm{O}$ conjunto de diretrizes e metas retratam a carência de organicidade interna do Plano, na medida em que várias metas são reiteradas, por vezes superpostas, e, em outros casos, as metas não apresentam a devida articulação interna, especialmente no que se refere a concepções, financiamento e gestão. ${ }^{10}$

Não por acaso, o PNE aprovado contou, ainda, com significativas restrições à gestão e ao financiamento da educação, em função de nove vetos presidenciais ao que fora delineando. Como lógica e concepção política decorrentes desse processo, presenciamos a interpenetração entre as esferas pública e privada sob a égide do mercado, o que, na prática, abriu espaços para a consolidação de novas formas de privatização da educação, sobretudo da educação superior.

O PNE, apesar de apresentar metas de amplo alcance, indicando grandes desafios para a melhoria da educação nacional, configurou-se como plano formal, marcado pela ausência de mecanismos concretos 
de financiamento. ${ }^{11}$ Outro aspecto a ser realçado refere-se à dinâmica global de planejamento adotada, em que não se efetivou a organicidade orçamentária para dar concretude às metas do PNE, na medida em que o Plano não foi levado em conta no processo de elaboração do Plano Plurianual (PPA) e de suas revisões. Esse cenário é revelador de um dos seus grandes limites estruturais.

Por se configurar como um plano nacional para toda a educação, o PNE sinalizou metas a serem efetivadas pelos diferentes entes federados e, desse modo, em função da lógica política adotada e da não regulamentação do regime de colaboração, como previsto na Constituição $\mathrm{Fe}$ deral de 1988, apresenta limites na sua efetivação. Merece ser ressaltado, ainda, que a aprovação de planos estaduais e municipais, previstos no PNE como base para a sua organicidade, não se efetivou como política concreta na maior parte dos estados e municípios, e, desse modo, tal processo não contribuiu para o avanço na dinâmica de democratização do planejamento e da gestão da educação no país e para a ratificação do Plano como política de Estado.

Outro limite associado a essa lógica política faz-se presente na complexa relação estabelecida entre o ministério, suas secretarias e órgãos e as demais instâncias responsáveis pelas políticas educacionais nos estados e municípios (secretarias, conselhos etc.), bem como na superposição de programas e açóes no campo educacional que, por vezes, estruturam programas com concepçôes e finalidades político-pedagógicas contraditórias, não contribuindo para o avanço das políticas e da gestão na área. ${ }^{12}$

Em outros termos, o PNE aprovado não se constituiu como base e diretriz para políticas, planejamento e gestão da educação nacional nem foi acionado como tal pelos diferentes segmentos da sociedade civil e política brasileira. A esse respeito, as entidades educacionais, por exemplo, não efetivaram uma avaliação sistemática e global do Plano e de sua concretização. Não houve movimento em defesa do atual PNE, por exemplo, pelas entidades educacionais, que, ao contrário, advogaram, como estratégia política, em dado momento, a revogação do Plano aprovado, por entenderem que este dispositivo legal não traduzia o esforço político conduzido pela sociedade civil, em particular pelo Fórum Nacional em Defesa da Escola Pública, ${ }^{13}$ e que não se configurava como política de Estado mas era resultante de manobras governamentais no seu processo 
Avaliação do Plano Nacional de Educação 2001-2009: questôes estruturais e conjunturais...

de tramitação. Paradoxalmente, e tendo em vista a defesa da proposta de PNE da sociedade brasileira, a Carta resultante do IV CONED $^{14}$ sinaliza duas açôes políticas concretas, como plano de lutas, no sentido de se avançar no contexto do atual PNE: 1) Participar da elaboração dos planos estaduais e municipais referenciados no PNE: Proposta da Sociedade Brasileira, articulados, onde houver, com os respectivos Fóruns Estaduais e Municipais em Defesa da Escola Pública; 2) Lutar pela derrubada dos vetos presidenciais à Lei n. 10.172/2001 (PNE do governo). Ao defender a derrubada dos vetos, a posição indica um reposicionamento com relação à revogação do PNE, sem prejuízo da manutenção do PNE: Proposta da Sociedade Brasileira como a referência para as políticas educacionais.

Merece ser ressaltado, ainda, que o $\mathrm{V}$ CONED ${ }^{15}$ reafirma "os compromissos assumidos pelo Fórum Nacional em Defesa da Escola Pública, consubstanciados no PNE: Proposta da Sociedade Brasileira, (...)" e afirma que a função do governo "é cumprir a Constituição Federal, garantindo educação pública, gratuita, democrática, laica, de qualidade social, para todos(as), em todos os níveis e modalidades". Nesse contexto, reiterou o projeto de PNE da sociedade brasileira, em detrimento de avaliação mais efetiva do PNE em vigência.

Todos esses indicadores sinalizam para limites ${ }^{16}$ à educação nacional, traduzidos na proposição e materialização das políticas e do Plano, bem como os relacionados com a não regulamentação do regime de colaboração e com os marcos adotados para gestão e financiamento da educação nacional. Ou seja, o PNE foi secundarizado nos processos de gestão e decisão no âmbito do Executivo federal e não se corporificou em efetivos planos decenais de educação, nos âmbitos municipais e estaduais, como previsto na legislação. O cumprimento das metas e, sobretudo, as possíveis melhorias na qualidade da educação nacional efetivaram-se como resultantes de açōes e políticas governamentais stricto sensu, sem ter o Plano como o epicentro do processo político.

Tais processos e políticas encontram na complexa estrutura educacional brasileira, marcada pela lógica de gestão e organização estruturada sob o paradoxo da descentralização e da centralização, caminho fértil para a ação centralizadora da União, especialmente do Executivo federal, no processo de coordenação nacional de políticas na área educacional. Tal constatação, ao realçar a centralidade conferida à União, não ignora ou subestima as políticas propostas e efetivadas por estados e municípios, 
dentro de suas prerrogativas legais. Trata-se, portanto, de ao identificar o centralismo, ainda presente na política educacional, buscar mecanismos para a sua superação sem perder de vista a responsabilidade da União, como ente federado, em matéria de educação, pois como afirma Cury (2006, p. 113): "Afinal a educação é nacional porque se assenta em diretrizes e bases nacionais (XXIV do artigo 22, da Constituição Federal de 1988) e cuja elaboração é da competência privativa da União”.

Especificamente no tocante ao PNE, é fundamental destacar que sua aprovação, pelo Congresso Nacional, efetivou-se no Governo FHC por meio das estratégias políticas já delineadas e que sua efetivação ou não, se considerarmos a centralidade das políticas federais no campo educativo, obviamente que articuladas à ação de estados e municípios - responsáveis, no caso brasileiro, pela oferta majoritária da educação básica deram-se no Governo Lula, a partir de 2003.

A tradição do Estado brasileiro, de políticas e gestão como resultante das ações e prioridades governamentais, stricto sensu, em detrimento de efetivas políticas de Estado, sofre injunções as mais diversas das estruturas políticas, econômicas, sociais e culturais após a aprovação do Plano e corroboram para a manutenção dessa complexa tessitura política na medida em que o atual PNE não foi considerado a base e a diretriz política central, no planejamento e na implementação das ações educacionais. No tocante ao Governo Lula, é fundamental destacar que a aprovação do Plano de Desenvolvimento da Educação (PDE) ${ }^{17}$ consubstancia tal assertiva, na medida em que o PDE se configurou como um conjunto de programas direcionado a traduzir as prioridades da política governamental e que, neste sentido, não se definia como uma mera estratégia instrumental para o cumprimento das metas do PNE. Nessa direção, de acordo com o documento "PDE: razões, princípios e programas" (MEC, 2007, p. 7), o PDE

(...) pretende ser mais do que a tradução instrumental do Plano Nacional de Educação (PNE), o qual, em certa medida, apresenta um bom diagnóstico dos problemas educacionais, mas deixa em aberto a questão das ações a serem tomadas para a melhoria da qualidade da educação. É bem verdade (...), que o PDE também pode ser apresentado como plano executivo, como conjunto de programas que visam dar consequência às metas quantitativas estabelecidas naquele diploma legal, mas os enlaces conceituais propostos tornam evidente que não se trata, quanto à qualidade, de uma execução marcada pela neutralidade. Isso porque, de um 
Avaliação do Plano Nacional de Educação 2001-2009: questôes estruturais e conjunturais...

lado, o PDE está ancorado em uma concepção substantiva de educação que perpassa todos os níveis e modalidades educacionais e, de outro, em fundamentos e princípios historicamente saturados, voltados para a consecução dos objetivos republicanos presentes na Constituição, sobretudo no que concerne ao que designaremos por visão sistêmica da educação e à sua relação com a ordenação territorial e o desenvolvimento econômico e social.

Saviani (2007, p. 1.239), ao analisar o PDE, assinala:

Confrontando-se a estrutura do Plano Nacional de Educação (PNE) com a do Plano de Desenvolvimento da Educação (PDE), constata-se que o segundo não constitui um plano, em sentido próprio. Ele se define, antes, como um conjunto de ações que, teoricamente, se constituiriam em estratégias para a realização dos objetivos e metas previstos no PNE. Com efeito, o PDE dá como pressupostos o diagnóstico e o enunciado das diretrizes, concentrando-se na proposta de mecanismos que visam à realização progressiva de metas educacionais. Tive, porém, que introduzir o advérbio "teoricamente" porque, de fato, $O$ PDE não se define como uma estratégia para o cumprimento das metas do PNE. Ele não parte do diagnóstico, das diretrizes e dos objetivos e metas constitutivos do PNE, mas se compõe de ações que não se articulam organicamente com este. (Grifos nossos)

Ao longo do texto assumimos como eixo a educação, entendida como espaço de disputa, onde as políticas educacionais, como políticas públicas, traduzem, historicamente, os embates sociais mais amplos, entre as classes sociais, os diferentes atores, as conjunturas políticas, entre outros agentes. Destacamos, ainda, alguns limites dessas políticas, em especial no que se refere ao atual PNE, no que concerne a sua tramitação, concepção e secundarização no campo das políticas educacionais, em detrimento das políticas governamentais.

No caso brasileiro, destacamos que a ação governamental tem tido centralidade nas políticas educacionais, sobretudo as ações e os programas sem uma efetiva articulação com políticas mais amplas, que contem com a participação da sociedade. Neste contexto, o PNE traduz esse movimento, na medida em que se configurou, na qualidade de proposição, como uma política de Estado, mas, na prática, não se traduziu como mecanismo de regulação capaz de nortear as diretrizes de planejamento, gestão e efetivação das políticas educacionais, como se espera de um plano nacional que contribua para o pacto federativo. 
Avaliação do PNE e a construção de políticas de Estado

Sendo a educação entendida como um direito social, a proposição de políticas envolve, direta ou indiretamente, a ação da sociedade política e da sociedade civil e, em se tratando de um Estado federativo, implica, necessariamente, o envolvimento da União, dos estados, do Distrito Federal e dos municípios, como entes federados que se encarregam de tais políticas, em seus diferentes níveis e modalidades.

Com base no referencial teórico ressaltado neste artigo, e valendonos, sobretudo, de análises anteriores (Dourado, 2006), dos resultados da avaliação do PNE (2001-2008), buscamos situar a complexidade que envolve o processo de avaliação do PNE, entendido como política que não se circunscreve às políticas de governo, mas que tem nas ações desses entes, especialmente da União, mecanismos indutores ou não das diretrizes e metas contidas no Plano, ainda que este não tenha se convertido em instrumento efetivo de gestão das políticas educacionais.

De maneira geral, as avaliaçôes feitas sobre o PNE privilegiaram o protagonismo do governo federal na formulação, implementação e indução de políticas, programas e ações relacionados ao cumprimento das metas do PNE. ${ }^{18}$

Tal constatação remete para a necessidade de análises que englobem a participação dos demais entes federados e sugere o reconhecimento de que o PNE não se converteu, efetivamente, em uma política de Estado, no sentido lato, mas constituiu-se em um instrumento de luta em prol da construção das políticas. Isso não nos autoriza, contudo, a negligenciar diferentes encaminhamentos e políticas que, por seu turno, traduzem continuidades e mudanças nos eixos das políticas governamentais, envolvendo os governos FHC e Lula, e que, por sua vez, têm impacto nas diretrizes e metas do Plano, ainda que este não seja a referência básica a essas políticas.

Merecem destaque, por exemplo, políticas do Governo Lula referentes às mudanças na concepção e gestão das políticas, buscando romper com a lógica de políticas focalizadas no ensino fundamental e envolver toda a educação básica por meio da criação do Fundo de Manutenção e Desenvolvimento da Educação Básica e de Valorização dos Profissionais da Educação (FUNDEB); ${ }^{19}$ a adoção de políticas de inclusão social e de respeito à diversidade; políticas de formação inicial e contínua dos 
Avaliação do Plano Nacional de Educação 2001-2009: questôes estruturais e conjunturais...

trabalhadores em educação e à aprovação da emenda 59/2009, ${ }^{20}$ que ampliou a obrigatoriedade da educação nacional; políticas efetivas de expansão das instituiçōes federais de ensino, envolvendo a criação de universidades, IFETs, campi e cursos, e, paradoxalmente, a efetivação de novos mecanismos de financiamento do ensino superior privado, entre outras. Esta mudança na concepção da política potencializa alterações no escopo do atendimento das diretrizes e metas do PNE e, em alguns casos, sinaliza para o descompasso entre elas e as políticas eventualmente propostas naquele Plano.

Tendo em vistas o referencial aqui adotado, as análises feitas no tocante aos limites do PNE, o Documento Final da CONAE, destacamos que o novo PNE deverá, por meio da garantia de processos participativos que envolvam os diferentes segmentos da sociedade brasileira, buscar se constituir em política de Estado, sem perder de vista a existência de limites estruturais resultantes da lógica e legalidade capitalista, que assegure, entre outros, os seguintes princípios e políticas:

- A efetivação do Sistema Nacional de Educação ${ }^{21}$ e a instituição do Fórum Nacional de Educação como instância máxima de deliberação do SNE;

- A regulamentação do regime de colaboração e cooperação entre os entes federados;

- A ampliação do investimento em educação pública em relação ao PIB de modo a garantir $10 \%$ do PIB para a educação nacional, bem como a efetiva regulação democrática da educação nacional;

- A defesa de educação democrática e de qualidade, tendo por eixos a inclusão, a diversidade e a igualdade, bem como a instituição de um sistema nacional de avaliação em sintonia a esses princípios de modo a assegurar, por meio de políticas integradas e afirmativas, melhoria no acesso e permanência com sucesso para todos; ${ }^{22}$

- A consolidação de políticas e programas de formação, desenvolvimento profissional e valorização dos trabalhadores da educação, incluindo planos de carreira e remuneração compatíveis. ${ }^{23}$ 
No tocante a gestão e financiamento da educação básica, incluindo as etapas e modalidades de educaçãa ${ }^{24}$ que a constituem:

- o redimensionamento dos recursos, por meio da consolidação do FUNDEB e da otimização da relação entre os entes federados, consolidando o financiamento da educação básica e ampliando o aporte financeiro por parte da União, ${ }^{25}$ bem como a efetivação de um padrão de custo-aluno indissociável da qualidade;

- à educação infantil, incluindo a consolidação de programas específicos direcionados à expansão com qualidade para a etapa da educação básica;

- a consolidação de políticas visando à garantia da ampliação da escolarização obrigatória no país, que prevê, pela Emenda Constitucional n. 59/2009, educação básica obrigatória e gratuita dos 4 (quatro) aos 17 (dezessete) anos de idade, assegurada inclusive sua oferta gratuita para todos os que a ela não tiveram acesso na idade própria, por meio de estabelecimento de diretrizes, políticas e ações destinadas, dentre outras, à melhoria do ensino fundamental e de sua consolidação como etapa de formação ampliada de oito para nove anos; ao apoio à reorganização e ampliação do ensino médio e da educação profissional.

É fundamental, nesse contexto, garantir as condiçôes objetivas para que tais políticas direcionadas à expansão da obrigatoriedade contribuam para a efetivação das diferentes modalidades de educação básica e, no tocante à educação infantil, não signifiquem a escolarizaçăo da educação infantil, bem como a desobrigação dos entes federados, em especial dos municípios, com a expansão e melhoria da oferta da educação de 0 a 3 anos.

No tocante à educação superior, considerando o cenário de diferenciação, diversificação e privatização, ${ }^{26}$ entende-se que o novo PNE, em suas diretrizes e metas, deve assegurar a democratização e a melhoria desse nível por meio de um novo ethos acadêmico a partir da consolidação:

- de novos marcos para o financiamento desse nível de ensino, incluindo garantia da subvinculação de recursos para o setor público;

- da autonomia universitária nos marcos da CF/88; 
Avaliação do Plano Nacional de Educação 2001-2009: questôes estruturais e conjunturais...

- de políticas e programas para a educação superior, reorientados a fim de democratizar o acesso e a inclusão social em um cenário fortemente marcado pela privatização do ensino, incluindo, neste contexto, apoio efetivo às políticas de ações afirmativas, expansão das instituições públicas por meio de interiorização e ampliação de vagas e recursos, apoio estudantil; ${ }^{27}$

- de um Sistema Nacional de Avaliação, que articule a avaliação da graduação e da pós-graduação e a educação básica, resguardadas as especificidades desses níveis de ensino, por meio de processos que contribuam para o desenvolvimento da ciência e tecnologia e para a melhoria dos processos formativos;

- e expansão da pós-graduação e da pesquisa, do intercâmbio nacional e internacional de pesquisadores e estudantes, por meio de fortalecimento das agências de fomento, especialmente da CAPES e do CNPq.

Considerando a agenda das políticas educacionais brasileiras, e objetivando avançar na proposição e materialização de políticas de Estado para a educação nacional, ressaltamos, ainda, a necessidade de retomar e reafirmar os princípios destacados no Documento Final da Conferência Nacional de Educação (CONAE, 2010, p. 35-36), ${ }^{28}$ indicando as bases para a construção do novo PNE, o qual: deve ter vigência decenal e ser expressão de uma política de Estado que garanta a continuidade da execução e da avaliação de suas metas perante as alternâncias governamentais e relações federativas; deve ser entendido como uma das formas de materialização do regime de colaboração entre sistemas e de cooperação federativa; deve ser resultado de ampla participação e deliberação coletiva da sociedade brasileira, incluindo, nesse processo, as conferências de educação, como loci constitutivos e constituintes do processo de discussão, elaboração e aprovação do PNE; deve avançar na correção de deficiências e lacunas do atual Plano, como também contribuir para o aprimoramento, o avanço e a organicidade das políticas educacionais em curso no país.

Aliada a esse processo, ressalta-se a importância de se construir e consolidar um novo PNE, como política de Estado, direcionado a garantir a expansão e democratização do acesso e da permanência em todos os níveis e modalidades da educação, dada a dívida histórica do Estado brasileiro. Este Plano, articulado a políticas sociais mais amplas, deverá, 
ainda, dar especial atenção a que essas diretrizes, ações e metas contribuam para a superação das desigualdades regionais e intrarregionais no campo educativo.

Em contrapartida, objetivando a compreensão e análise mais profundas das políticas e do Plano, na engenharia jurídica e de gestão que permeiam os processos de disputa e de efetivação do direito à educação no país, é fundamental avançar em estudos, pesquisas e demais processos avaliativos processuais, por meio de investigação contextualizada do cenário macro, das políticas governamentais e de suas interconexões com o PNE, considerando, nesse processo, as bases estruturais constitutivas deste - suas lacunas, seus limites e suas possibilidades - como política de Estado, de modo a contribuir para a sinalização de marcos de organização e gestão das políticas educacionais a serem propostas e efetivadas nos diferentes níveis de governo.

\section{Considerações finais}

A complexificação do atual cenário de construção das políticas públicas de educação, e no seu bojo do PNE (suas diretrizes e metas), configura-se tarefa desafiadora a ser construída coletivamente, envolvendo a sociedade civil e política, tendo em vista a superação dos limites do atual Plano, que, como discutimos, apresenta descompasso entre o proposto e o efetivado, uma vez que tal processo resultou da constatação de que as prioridades das políticas educacionais adotadas pelos governos, em especial o federal, não tiveram o PNE como indutor central de suas ações político-pedagógicas, e de que a dinâmica e a lógica do sistema educativo, marcado pelo binômio descentralização/centralização, em que pesem importantes avanços após a aprovação do Plano, não foram superadas, requerendo, nesse processo, de modo concomitante, a regulamentação do regime de colaboração e a construção de um Sistema Nacional de Educação, de modo a constituir condições políticas e de gestão que contribuam para a efetivação da melhoria nos diferentes níveis e modalidades que caracterizam a educação nacional.

Assim, em que pesem os limites referentes ao PNE como efetiva política de Estado, aqui apresentados, resultado do processo de tramitação, da ausência de centralidade conferida a ele na efetivação de políticas, dos limites político-econômicos vigentes à regulamentação da ação 
Avaliação do Plano Nacional de Educação 2001-2009: questôes estruturais e conjunturais...

dos entes federados sob a ótica da cooperação e colaboração, como previsto na Constituição Federal de 1988, é fundamental ressaltar que a aprovação do PNE suscitou, paradoxalmente, novos marcos para os processos de organização e gestão da educação nacional. A este respeito, a CONAE, ao dar centralidade à construção do novo PNE como política de Estado, sinaliza a importância e, ao mesmo tempo, revela a necessidade histórica de superação dos atuais limites do plano vigente, no que concerne à sua proposição e materialização.

Em contrapartida, destacamos a importância dos processos de avaliação desenvolvidos sobre o PNE e, ao mesmo tempo, entendemos que se faz necessário avançar na consolidação e no refinamento de processos avaliativos e de construção das políticas públicas educacionais, incluindo a complexificação e atualização de indicadores educacionais, a análise global e articulada entre diferentes políticas, programas, açôes envolvendo os diferentes entes federados, no que concerne a proposição e materialização, permitindo o desenvolvimento de estudos e análises que desvelem a complexa relação entre as opçôes e prioridades das ações governamentais, os nexos entre o Plano, as açōes, as políticas e os programas, os interesses em disputa e os limites decorrentes do contexto em que são forjadas as possibilidades para a concretização das políticas. Sob tal ponto de vista, a complexificação do processo analítico, propositivo avaliativo das políticas educacionais e, particularmente, do PNE deve extrapolar as açôes, as políticas e os programas circunscritos à esfera educacional traduzidas hegemonicamente pela ação do governo federal -, requerendo, desse modo, análises mais globais, capazes de situá-las no âmbito das demais políticas sociais e econômicas mais amplas.

\section{Recebido em agosto de 2010 e aprovado em setembro de 2010.}

\section{Notas}

1. É importante situar a ciência na sua dupla dimensão: 1) a da produção histórico-social, fruto de exigências de natureza técnica, prática e ideológica e 2) a da episteme, condicionada por exigências internas de cientificidade.

2. Estado entendido sob a concepção gramsciana, como expressão da correlação de forças contraditórias, estendendo-se além dos limites da classe dominante, a partir da força e do consenso, ou seja, da hegemonia encouraçada de coerção. Nesse contexto, o Estado ampliado (integral) não se reduz ao governo, constituindo-se, ele mesmo, na expressão das relaçôes sociais contraditórias, por meio de atividades e ações políticas (práticas e teóricas), em que, 
de um lado, as classes dirigentes se mantêm e se justificam e, de outro, servem de espaço e força efetiva para a consciência e organização das classes dominadas.

3. Ver Frigotto (1995).

4. Vários estudos e pesquisas, sobretudo no campo das políticas e de gestão, ressaltam a complexa e contraditória lógica das políticas educacionais no Brasil, envolvendo abordagens diversas, no tocante ao direito à educação, concepções em disputa, organização e gestão, educação e trabalho, financiamento; ver, entre outros, Ferreira e Aguiar (2009), Ferreira e Oliveira (2009), Ferreira (2008), Oliveira e Santana (2010), Oliveira (2007), Sander (2007), Silva e Aguiar (2004), Oliveira e Adrião (2007), Gouveia, Souza e Tavares (2006), Oliveira e Duarte (1999), Dourado e Paro (2001) e Cunha (1999 e 2009).

5. A respeito, ver Barroso (2006), Dourado (2007, 2008 e 2009), Gomes e Azevedo (2009), Oliveira (2009) e Mundim (2009).

6. É importante destacar que os dois projetos apresentavam concepçóes distintas, o que se traduziu nas prioridades, diretrizes e metas mas, também, no diagnóstico e na compreensão dos nexos entre política, gestão e financiamento. A respeito de pontos centrais que se apresentavam no Projeto de PNE da Sociedade Brasileira, e que não se fizeram presentes no projeto do MEC e, consequentemente, no PNE aprovado, destacam-se, entre outros: a instituição do Sistema Nacional de Educação (SNE), concebido como expressão institucional do esforço organizado, autônomo e permanente do Estado e da sociedade brasileira pela educação; o Fórum Nacional de Educação como instância máxima deliberativa da política educacional brasileira, com ampla representação dos setores sociais envolvidos com a educação; a redefinição do Conselho Nacional de Educação como órgão normativo e de coordenação do SNE, estabelecendo nova composição e atribuições. A respeito do PNE, ver Plano Nacional de Educação - Proposta da Sociedade Brasileira (2000), Didonet (2000), Saviani (1998), Valente e Romano (2002), Mendonça (2002), Abicalil (2005) e Dourado (2006).

7. "A tradição patrimonial, a ofensiva governamental e a ação pouco propositiva da maioria parlamentar, no sentido de fazer representar as demandas da sociedade civil organizada, especialmente por meio das açôes do Fórum Nacional em Defesa da Escola Pública, resultaram em um Plano com questôes e limites estruturais significativos, no tocante ao plano propriamente dito, em sua acepção de Plano de Estado e, em seu bojo, na organicidade e articulação entre concepção, diretrizes e metas e o potencial de sua materialização, no que concerne, entre outros fatores, à gestão e ao financiamento da educação nacional" (Dourado, 2006, p. 31).

8. Destacam-se, nesse processo, a Lei n. 9.131/95, a LDB (9.394/96), decretos, resoluçóes e portarias, entre outras açōes.

9. A estrutura do PNE compreende: I - Introdução, com o histórico, os objetivos e as prioridades do PNE; II - Níveis de Ensino, que trata da Educação Básica (Educação Infantil, Ensino Fundamental e Ensino Médio) e da Educação Superior; III - Modalidades de Ensino (Educação de Jovens e Adultos, Educação a Distância e Tecnologias Educacionais, Educação Tecnológica e Formação Profissional, Educação Especial e Educação Indígena); IV - Magistério da Educação Básica (Formação dos Professores e Valorização do Magistério); V - Financiamento e Gestão; e VI - Acompanhamento e Avaliação do Plano.

10. A respeito, ver documento de avaliação do MEC (2010).

11. Ver, a respeito, MEC (2010).

12. A esse respeito, ver a análise (Dourado, 2007) e a avaliação pormenorizada de ações, programas e políticas do governo federal, bem como dos indicadores educacionais e das metas do PNE (MEC, 2010).

Educ. Soc., Campinas, v. 31, n. 112, p. 677-705, jul.-set. 2010

Disponível em <http://www.cedes.unicamp.br> 
Avaliação do Plano Nacional de Educação 2001-2009: questôes estruturais e conjunturais...

13. O FNDEP contava com concepção abrangente envolvendo, entre outros organismos, entidades COMO ANDE, ANFOPE, ANPAE, ANPED, CEDES, SBPC, ANDES-SN, CNTE, FASUBRA, UNE, UBES e ANPG. Segundo o documento Propostas emergenciais para mudanças na educação brasileira - FNDEP, o "Fórum Nacional em Defesa da Escola Pública, constituído em 1987, por entidades científicas, acadêmicas, profissionais, sindicais, estudantis e movimentos populares de âmbito nacional, vem atuando, ao longo desses 16 anos, na defesa intransigente da universalização da educação pública, gratuita, laica, com qualidade social, em todos os níveis. Organizado para atuar na Constituinte, este Fórum foi responsável pelas principais conquistas que os setores sociais, comprometidos com essa concepção de educação, conseguiram inserir na Constituição Federal de 1988. Teve papel decisivo na construção do Projeto de LDB (PL n. 1.258/88), que, embora tenha sido a expressão dos anseios da sociedade brasileira, foi substituído por outro, no Senado, elaborado e aprovado à revelia da sociedade, dando origem à Lei de Diretrizes e Bases da Educação Nacional (LDB) em vigor. Foi o Fórum Nacional em Defesa da Escola Pública que, antecipando-se ao governo federal, apresentou, em 1988, ao Congresso Nacional (Câmara dos Deputados) o PL n. 4.155/98: Plano Nacional de Educação - Proposta da Sociedade Brasileira".

14. IV Congresso Nacional de Educação - IV CONED: 23 a 26 de abril de 2002, São Paulo (SP).

15. V Congresso Nacional de Educação - V CONED: de 2 a 5 de maio de 2004, Recife (PE).

16. No tocante aos limites conjunturais, o FNDEP merece ser objeto de análises visando compreender as condições objetivas que contribuíram para a sua desativação - resultado da intensificação de disputas de concepções e estratégicas político-pedagógicas, sobretudo a partir de 2003 - bem como os vários movimentos em favor da sua rearticulação desenvolvidos pelas entidades acadêmicas e sindicais da área nos últimos anos.

17. A respeito da relação PDE/PNE ver, entre outros autores, Saviani (2007), Gracindo (2009), Silva e Alves (2009).

18. Vale ressaltar que o PNE foi objeto de avaliação por diferentes interlocutores. O documento de avaliação do MEC (2010a) indica as seguintes análises sobre o Plano examinadas na avaliação do PNE 2001-2008 realizada: 1) realização de estudo sobre a implementação do PNE pela Consultoria Legislativa, por solicitação da Comissão de Educação e Cultura da Câmara dos Deputados, publicado em 2004; 2) Colóquio Nacional sobre Mecanismos de Acompanhamento e Avaliação do Plano Nacional de Educação, realizado em Brasília, em 2005, sob a responsabilidade da Coordenação-Geral de Articulação e Fortalecimento Institucional dos Sistemas de Ensino (CAFISE) da SEB/MEC; 3) Seminários Regionais de Acompanhamento e Avaliação do PNE e dos Planos Decenais Correspondentes, realizados nas cinco regióes do país, em 2006, e coordenados pelo MEC/SEB/DASE/CAFISE; 4) diagnósticos regionais da situação educacional diante das metas do PNE, realizados pelo Centro de Planejamento e Desenvolvimento Regional (CEDEPLAR), em 2006; 5) realização de ciclos de debates pelo Conselho Nacional de Educação (CNE) com vistas a subsidiar o MEC no envio de propostas para o Congresso Nacional, em setembro e outubro de 2005; 6) avaliação preliminar do PNE, período 2001 a 2005, coordenada pela DTDIE/INEP, com a participação de especialistas em educação. Merecem ser ressaltados, ainda, na avaliação do MEC (2010 a), o documento-base do CNE com propostas para o PNE; o esforço empreendido pelo Congresso Nacional, por meio de ações e seminários direcionados à articulação com a sociedade, com vistas à avaliação e à construção do novo PNE e à importância histórica da Conferência Nacional de Educação, que, precedida de conferências municipais e estaduais, procedeu à avaliação das políticas educacionais e, no seu bojo, do PNE, e propôs, em seu Documento Final (MEC, 2010), diretrizes concretas para a construção coletiva e democrática do novo PNE.

19. A respeito do Fundeb, ver Fernandes (2009) e Pinto (2009). 
20. No que tange à Emenda n. 59/2009, é fundamental destacar os avanços no tocante a acesso, financiamento e gestão, na medida em que a referida emenda estabelece: 1) a ampliação da educação básica obrigatória e gratuita dos 4 (quatro) aos 17 (dezessete) anos de idade, assegurada inclusive sua oferta gratuita para todos os que a ela não tiveram acesso na idade própria; 2) que a distribuição dos recursos públicos assegurará prioridade ao atendimento das necessidades do ensino obrigatório, no que se refere a universalização, garantia de padrão de qualidade e equidade, nos termos do Plano Nacional de Educação; 3) que o Plano Nacional de Educação, de duração decenal, com o objetivo de articular o Sistema Nacional de Educação em regime de colaboração e definir diretrizes, objetivos, metas e estratégias de implementação para assegurar a manutenção e o desenvolvimento do ensino em seus diversos níveis, etapas e modalidades por meio de ações integradas dos poderes públicos das diferentes esferas federativas. E inova, substantivamente, como resultante dessas ações integradas a prever "o estabelecimento de meta de aplicação de recursos públicos em educação como proporção do Produto Interno Bruto".

21. A respeito do SNE, ver Abicalil (2009), Cury (2009), Gracindo (2010) e Saviani (2009).

22. A respeito, ver Clímaco et al. (2010), Oliveira (2010), Gomes (2010), Dourado, Oliveira e Santos (2007).

23. A esse respeito, ver Aguiar e Scheibe (2010), Vieira (2010), Pino (2008), Dourado (2008) e Freitas (2007).

24. Educação especial, educação indígena, educação do campo, educação profissional, educação de jovens e adultos, educação ambiental. Bem como políticas direcionadas à educação em direitos humanos, educação prisional, a crianças, adolescentes e jovens em situação de risco, a gênero e diversidade sexual, entre outros segmentos.

25. É importante ressaltar, a respeito, estudos que indicam limites ao FUNDEB, sobretudo no que concerne, entre outros, à participação da União e aos coeficientes relativos às diferentes etapas e modalidades (Pinto, 2007 e 2009); estudos que sinalizam para a necessidade de estabelecimento e garantia de um padrão de custo aluno-qualidade (Carreira \& Pinto, 2007). Outra análise importante refere-se à necessária definição dos referenciais de qualidade articulados à vinculação de recursos financeiros como condição para a efetiva expansão do sistema (Amaral, 2010).

26. Há uma vasta produção na área que discute, a partir de vários ângulos, as condições objetivas, concepçôes, expansão, privatização, processos de gestão, autonomia, reforma e financiamento da educação superior, carreira, nos governos $\mathrm{FHC}$ e Lula. A esse respeito ver, entre outros autores, Cunha (2003 e 2004), Amaral (2003 e 2009), Sguissardi (2009), Bittar, Oliveira e Morosini (2008), Mancebo e Fávero (2004); Oliveira e Catani (2002), Dourado (2002, 2003 e 2009), Sguissardi e Silva Júnior (2001 e 2009), Mancebo, Silva Júnior e Oliveira (2008), Mancebo et al. (2009), Chaves e Silva Júnior (2008).

27. Tal perspectiva implica a efetivação de açôes ainda no tocante à expansão pública da educação superior.

28. Documento Final da CONAE (CONAE, 2010).

\section{Referências}

\section{ABICALIL, C.A. Plano Nacional de Educação na República Federativa do Brasil: instrumento de retórica ou política pública para a realização}


Avaliação do Plano Nacional de Educação 2001-2009: questôes estruturais e conjunturais...

do direito à educação básica. 2005. Dissertação (Mestrado em Educação) - Universidade de Brasília, Brasília, DF.

ABICALIL, C.A. Construindo o Sistema Nacional Articulado de Educação. In: CONFerÊnCia NaCiOnal De EdUCAÇÃo (CONAE). Brasília, DF: MEC, 2009. p. 75-100.

AGUIAR, M.A.S.; SCHEIBE, L. Formação e valorização: desafios do PNE 2011-2020. Retratos da Escola, Brasília, DF, v. 4, n. 6, p. 77-90, jan./jul. 2010.

AMARAL, N.C. Financiamento da educação superior: Estado x mercado. São Paulo: Cortez, 2003.

AMARAL, N.C. Autonomia-avaliação-financiamento: em FHC e Lula. In: Dourado, L.F (Org.). Politicas e gestão da educação no Brasil: novos marcos regulatórios. São Paulo: Xamã, 2009. p. 169-182.

AMARAL, N.C. Financiamento da educação básica e o PNE 2011-2020. Retratos da Escola, Brasília, DF, v. 4, n. 6, p. 123-141, jan./jul. 2010.

AZEVEDO, J.M.L. A educação como politica pública. São Paulo: Cortez, 1997.

AZEVEDO, J.M.L. Reflexões sobre políticas públicas e o PNE. Retratos da Escola, Brasília, DF, v. 4, n. 6, p. 27-35, jan./jul. 2010.

BARROSO, J. (Org.). A regulação das políticas públicas de educação: espaços, dinâmicas e atores. Lisboa: Educa, 2006.

BITTAR, M.; OLIVEIRA, J.F.; MOROSINI, M. (Org.). Educação superior no Brasil: 10 anos pós-LDB. Brasília, DF: INEP, 2008. v. 1, p. 165-182. BRASIL. Câmara dos Deputados. Avaliação técnica do Plano Nacional de Educação. Brasília, DF: Câmara dos Deputados; Coordenação de Publicações, 2004. 189p. (Ação Parlamentar, n. 294).

BRASIL. Câmara dos Deputados. O legislativo e a sociedade construindo juntos o novo Plano Nacional de Educação. Brasília, DF: Câmara dos Deputados; Coordenação de Publicações, 2009. 238p. (Ação Parlamentar, n. 402).

BRASIL. Constituição (1988). Constituição da República Federativa do Brasil. Brasília, DF: Senado, 1988. 
BRASIL. Lei n. 9.394/96, de 20 de dezembro de 1996. Estabelece as diretrizes e bases da educação nacional. Diário Oficial da União, Brasília, DF, 23 dez. 1996. p. 27894.

BRASIL. Lei n. 10.172, de 9 janeiro de 2001. Institui o Plano Nacional de Educação e dá outras providências. Diário Oficial da União, Brasília, DF, 10 jan. 2001.

BRASIL. Ministério da Educação. O Plano de desenvolvimento da educação: razões, princípios e programas. Brasília, DF: MEC, 2007.

BRASIL. Ministério da Educação. Conselho Nacional de Educação. Indicaçôes para subsidiar a construção do Plano Nacional de Educação 20112020. Disponível em: <http://portal.mec.gov.br/dmdocuments/pne_ 200809.pdf>. Acesso em: 15 ago. 2010.

BRASIL. Ministério da Educação. Instituto Nacional de Estudos e Pesquisas Educacionais (INEP). Os desafios do Plano Nacional de Educação. Brasília, DF: MEC/INEP, 2004.

BRASIL. Ministério da Educação. Instituto Nacional de Estudos e Pesquisas Educacionais (INEP). Avaliação do Plano Nacional de Educação: 2001/2008. Brasília, DF: MEC/INEP, 2010. Disponível em: <http:// portal.mec.gov.br/index.php?option $=$ com_content \&view=article\&id= 14950:8o-seminario-reuni-27-a-29-de-janeiro-de-2010-universidadesfederais-consolidacao-e-expansao-2011-2020-subsidios-para-o-planonacional-de-educacao \&catid $=219 \&$ Itemid $=86>$. Acesso em: 20 ago. 2010 .

CARDOSO, M.L. Ideologia do desenvolvimento - Brasil: JK-JQ. 2. ed. Rio de Janeiro: Paz \& Terra, 1978.

CARREIRA, D.; PINTO, J.M.R. Custo aluno-qualidade inicial: rumo à educação pública de qualidade no Brasil. São Paulo: Global, 2007. $127 \mathrm{p}$.

CARTA do IV Congresso Nacional de Educação. Disponível em: $<$ http://www.google. $c o m /$ search? client=safari\&rls=en \&q=carta + iv + coned\&ie=UTF-8\&oe=UTF-8>. Acesso em: 12 ago. 2010.

CARTA do V Congresso Nacional de Educação. Disponível em: $<$ http://www.google. $\operatorname{com} /$ search? client=safari\&rls=en $\& \mathrm{q}=\mathrm{carta}+\mathrm{v}+$ coned\&ie=UTF-8\&oe=UTF-8>. Acesso em: 12 ago. 2010. 
Avaliação do Plano Nacional de Educação 2001-2009: questôes estruturais e conjunturais...

CHAVES, V.L.J.; SILVA JÚNIOR, J.R. (Org.). Educação superior no Brasil e diversidade regional. Belém do Pará: UFPA, 2008. p. 389408.

CLÍMACO, A.C.A. et al. Educação básica de qualidade: desafios e proposições para o novo PNE. Retratos da Escola, Brasília, DF, v. 4, n. 6, p. 109-121, jan.-jul. 2010.

CONFERÊNCIA NACIONAL DE EDUCAÇÃO (CONAE), 2010, Brasília, DF. Construindo o Sistema Nacional Articulado de Educação: o Plano Nacional de Educação, diretrizes e estratégias; Documento Final. Brasília, DF: MEC, 2010.

CONGRESSO NACIONAL DE EDUCAÇÃO. Plano Nacional de Educação: proposta do II CONED. Belo Horizonte: CONED, 1998.

CONGRESSO NACIONAL DE EDUCAÇÃO. Plano Nacional de Educação: proposta da Sociedade Brasileira, 2000.

CUNHA, L.A. Educação, Estado e democracia no Brasil. São Paulo: Cortez; Brasília, DF: FLACSO; Niterói: EDUFF, 1999.

CUNHA, L.A. O ensino superior no octênio FHC. Educação \& Sociedade, Campinas, v. 24, n. 82, p. 37-61, 2003.

CUNHA, L.A. Desenvolvimento desigual e combinado no ensino superior: Estado e mercado. Educação \& Sociedade, Campinas, v. 25, n. 88, p. 795-817, 2004.

CURY, C.R.J. Federalismo político e educacional. In: Ferreira, N.S.C. Políticas públicas e gestão da educação: polêmicas, fundamentos e análises. Brasília, DF: Liber Livro, 2006. p. 113-129.

CURY, C.R.J. Sistema Nacional de Educação: desafio para uma educação igualitária e federativa. Educação \& Sociedade, Campinas, v. 29, n. 105, p. 1187-1209, set./dez. 2008.

CURY, C.R.J. Os desafios da construção de um Sistema Nacional de Educação. In: CONFERÊNCIA NACIONAL DE EDUCAÇÃO (CONAE). Brasília, DF: MEC, 2009. v.1, p. 12-31.

DIDONET, V. Apresentação: Plano Nacional de Educação. Brasília, DF: Plano, 2000. 
DOURADO, L.F. Reforma do Estado e as políticas para a educação superior no Brasil nos anos 90. Educação \& Sociedade, Campinas, v. 23, n. 80 , p. $235-253$, set. 2002.

DOURADO, L.F. Plano Nacional de Educação: avaliações e retomada do protagonismo da sociedade civil organizada na luta pela educação. In: Ferreira, N.S.C. (Org.). Políticas públicas e gestão da educação: polêmicas, fundamentos e análises. Brasília, DF: Liber Livro, 2006. p. 21-50.

DOURADO, L.F. Políticas e gestão da educação básica no Brasil: limites e perspectivas. Educação \& Sociedade, Campinas, v. 28, n. 100, p. 921-946, 2007.

DOURADO, L.F. Políticas e gestão da educação superior a distância: novos marcos regulatórios?. Educação \& Sociedade, Campinas, v. 29, n. 104, p. 891-917, 2008.

DOURADO, L.F. (Org.). Políticas e gestão da educação no Brasil: novos marcos regulatórios da educação no Brasil. São Paulo: Xamã, 2009.

DOURADO, L.F.; PARO, V.H. (Org.). Políticas públicas e educação básica. São Paulo: Xamã, 2001. 158p

DOURADO, L.F; OLIVEIRA, J.F.; SANTOS, C.A. A qualidade da educação: conceitos e definiçōes. Série Documental (INEP), Brasília, DF, v. 24, n. 22, p. 5-34, 2007.

FERNANDES, F.C. O FUNDEB como política pública de financiamento da educação básica. Retratos da Escola, Brasília, DF, v. 3, n. 4, p. 2338, jan./jun. 2009.

FERREIRA, E.B.; OLIVEIRA, D.A. Crise da escola e politicas educativas. Belo Horizonte: Autêntica, 2009. 315p.

FERREIRA, N.S.C. Politicas públicas e gestão da educação: polêmicas, fundamentos e análises. Brasília, DF: Liber Livro, 2006.

FERREIRA, N.S.C. (Org.). Gestão democrática da educação: atuais tendências, novos desafios. 6. ed. São Paulo: Cortez, 2008.

FERREIRA, N.S.C.; AGUIAR, M.A. (Org.). Gestão da educação: impasses, perspectivas e compromissos. 7. ed. São Paulo: Cortez, 2009. 
Avaliação do Plano Nacional de Educação 2001-2009: questôes estruturais e conjunturais...

FÓRUM NACIONAL EM DEFESA DA ESCOLA PUBLICA (FNDEP). Propostas emergenciais para mudanças na educação brasileira. Disponível em: <http://www.aduff.org.br/documentos/forum_esc.htm>. Acesso em: 22 ago. 2010. (Documento do Fórum Nacional em Defesa da Escola Pública).

FREITAS, H.C.L. A (nova) política de formação de professores: a prioridade postergada. Educação \& Sociedade, Campinas, v. 28, n. 100, p. 1203-1230, 2007.

FRIGOTTO, G. Educação e a crise do capitalismo real. São Paulo: Cortez, 1995.

FRIGOTTO, G.; MOLINA, H. Estado, educação e sindicalismo no contexto da regressão social. Retratos da Escola, Brasília, DF, v. 4, n. 6, p. 37-51, jan./jul. 2010.

GRACINDO, R.V. PNE e PDE: aproximações possíveis. In: DouRADo, L.F. (Org.). Políticas e gestão da educação no Brasil: novos marcos regulatórios da educação no Brasil. São Paulo: Xamã, 2009. p. 75-99.

GRACINDO, R.V. O Sistema Nacional de Educação e a escola pública de qualidade para todos. Retratos da Escola, Brasília, DF, v. 4, n. 6, p. 53-64, jan./jul. 2010.

GRAMSCI, A. Concepção dialética da história. Rio de Janeiro: Civilização Brasileira, 1986.

GOMES, A.; AZEVEDO, J.L. Notas teóricas sobre regulação e educação superior. In: Dourado, L.F. (Org.). Politicas e gestão da educação no Brasil: novos marcos regulatórios da educação no Brasil. São Paulo: Xamã, 2009. p. 183-191.

GOMES, N.L. Trabalho, educação e diversidade: um longo trabalho pela frente. Retratos da Escola, Brasília, DF, v. 4, n. 6, p. 143-155, jan./ jul. 2010.

GOUVEIA, A.B.; SOUZA, A.R.; TAVARES, T.M. (Org.). Conversas sobre financiamento da educação no Brasil. Curitiba: UFPR, 2006.

MANCEBO, D.; FAVERO, M.L.A. (Org.). Universidade: políticas, avaliação e trabalho docente. São Paulo: Cortez, 2004. 303p. 
MANCEBO, D.; SILVA JUNIOR, J.R.; OLIVEIRA, J.F. (Org.). Reformas e políticas: educação superior e pós-graduação. Rio de Janeiro: ANPEd; Campinas: Átomo \& Alínea, 2008.

MANCEBO, D. et al. (Org.). Reformas da educação superior: cenários passados e contradições do presente. São Paulo: Xamã, 2009. 152p.

MENDONÇA, E. Plano Nacional de Educação: desdobramentos na política educacional. São Bernardo do Campo: UMESP; Biblioteca ANPAE, 2002.

MONLEVADE, J.A. PNE: feito para não acontecer. Brasília, DF, 23 fev. 2005. (mimeo.).

MUNDIM, M.A.P. Políticas de regulação na educação: uma análise da organização da escola em ciclos em Goiânia no período de 1998-2008. 2009. Tese (Doutorado) - Faculdade de Educação, Universidade Federal de Goiânia, Goiânia.

OLIVEIRA, D.A. Gestão das políticas públicas educacionais: ação pública, governance e regulação. In: Dourado, L.F. (Org.). Políticas e gestão da educação no Brasil: novos marcos regulatórios da educação no Brasil. São Paulo: Xamã, 2009. p. 11-29.

OLIVEIRA, D.A.; DUARTE, R.T. (Org.). Politica e trabalho: administração dos sistemas públicos de Educação Básica. Belo Horizonte: Autêntica, 1999.

OLIVEIRA, J.F. A educação básica e o PNE 2011-2020: políticas de avaliação democrática. Retratos da Escola, Brasília, DF, v. 4, n. 6, p. 91-108, jan./jul. 2010.

OLIVEIRA, J.F.; CATANI, A.M. Educação superior no Brasil: reestruturação e metamorfose das universidades públicas. Petrópolis: Vozes, 2002. 102p.

OLIVEIRA, R.P. Da universalização do ensino fundamental ao desafio da qualidade: uma análise histórica. Educação \& Sociedade, Campinas, v. 28, n. 100, p. 661-690, 2007.

OLIVEIRA, R.P.; ADRIÃO, T. (Org.). Gestão, financiamento e direito à educação: análise da Constituição Federal e da LDB. 3. ed. São Paulo: Xamã, 2007. 143p. 
Avaliação do Plano Nacional de Educação 2001-2009: questôes estruturais e conjunturais...

OLIVEIRA, R.P.; SANTANA, W. (Org.). Educação e federalismo no Brasil: combater as desigualdades, garantir a diversidade. Brasília, DF: UNESCO, 2010. 299p.

PINO, I.R. As TIC na formação a distância: reflexões contemporâneas. Retratos da escola, Brasília, DF, v. 2, n. 4, p. 109-120, 2008.

PINTO, J.M.R. A política recente de fundos para o financiamento da educação e seus efeitos no pacto federativo. Educação \& Sociedade, Campinas, v. 28, n. 100, p. 877-897, 2007.

PINTO, J.M.R. O financiamento da educação no Governo Lula. Revista Brasileira de Política e Administração da Educação, Brasília, DF, v. 25, n. 2, p. 323-340, 2009.

SANDER, B. A pesquisa sobre politica e gestão da educação no Brasil: temáticas, resultados e perspectivas. Trabalho apresentado no IV Congresso Luso-Brasileiro de Política e Administração da Educação, 2007, Lisboa. 24p. (mimeo)

SAVIANNI, D. Da nova LDB ao novo Plano Nacional de Educação: por uma política educacional. Campinas: Autores Associados, 1998.

SAVIANI, D. O Plano de Desenvolvimento da Educação: análise do projeto do MEC. Educação \& Sociedade, Campinas, v. 28, n. 100, out. 2007. Disponível em: <http://www.scielo.br/scielo. php?script=sci_ arttext\&pid=S010173302007000300027\&lng=pt\&nrm = iso $>$. Acesso em: 22 ago. 2010.

SAVIANI, D. Sistema de Educação: subsídios para a Conferência Nacional de Educação. Brasília, DF: MEC, 2009. p. 34-74.

SGUISSARDI, V. Universidade Brasileira no século XXI: desafios do presente. São Paulo: Cortez, 2009.

SGUISSARDI, V.; SILVA JUNIOR, J.R. São Paulo: novas faces da educação superior no Brasil - reforma do Estado e mudança na produção. São Paulo: Cortez; Usf, 2001.

SGUISSARDI, V.; SILVA JUNIOR, J.R. Trabalho intensificado nas federais: pós-graduação e produtivismo acadêmico. São Paulo: Xamã, 2009. 271p. 
SILVA, A.F.; ALVES, M.F. Análise do PNE e do PDE: continuidades e rupturas. In: Dourado, L.F. (Org.). Políticas e gestão da educação no Brasil: novos marcos regulatórios da educação no Brasil. São Paulo: Xamã, 2009. p. 101-118.

SILVA, A.M.; AGUIAR, M.A.S. (Org.). Retrato da escola no Brasil. Brasília, DF: CNTE, 2004.

SOUZA, P.R. A revolução silenciada: educação no Brasil - 1995-2002. São Paulo: Prentice Hall, 2005.

VALENTE, I.; ROMANO, R. PNE: Plano Nacional de Educação ou carta de intenção?. Educação \& Sociedade, Campinas, v. 23, n. 80, p. 97-108, set. 2002 .

VIEIRA, J.M.D. Gestão democrática na perspectiva dos trabalhadores em educação. Retratos da Escola, Brasília, DF, v. 4, n. 6, p. 65-76, jan.jul. 2010. 